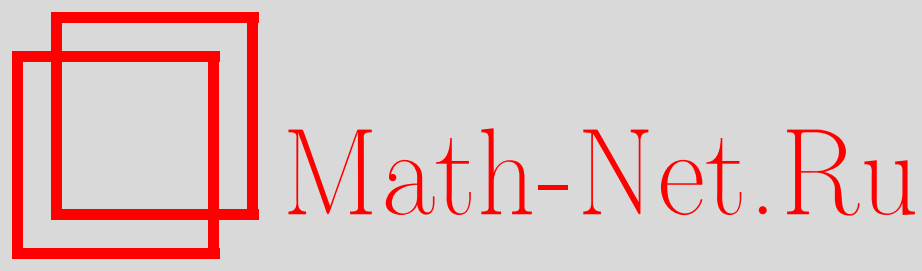

К юбилею Игоря Викторовича Тютина, ТМФ, 2016, том 187, номер 2, 197-199

DOI: https://doi.org/10.4213/tmf9218

Использование Общероссийского математического портала Math-Net.Ru подразумевает, что вы прочитали и согласны с пользовательским соглашением http://www . mathnet.ru/rus/agreement

Параметры загрузки:

IP : 35.173 .137 .237

26 апреля 2023 г., 12:11:43

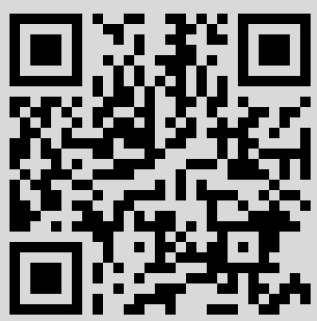




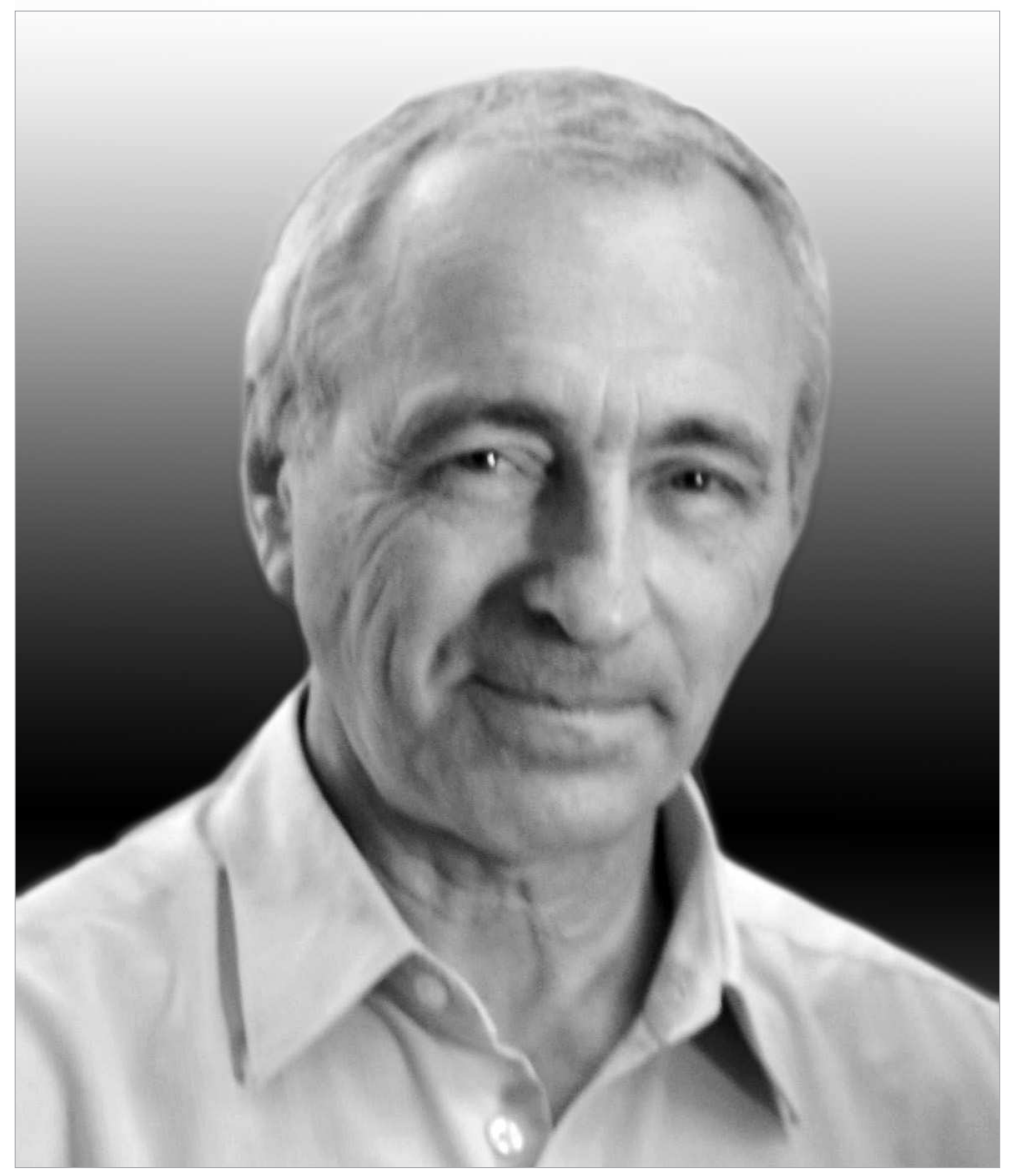

Фото О. И. Лойко

\section{К ЮБИЛЕЮ ИГОРЯ ВИКТОРОВИЧА ТЮТИНА}

24 августа 2015 года исполнилось 75 лет Игорю Викторовичу Тютину - замечательному физику-теоретику, ученому и педагогу, члену редакционной коллегии журнала "Теоретическая и математическая физика".

В наше время задачи квантовой теории поля уже невозможно даже сформулировать, не опираясь на результаты И.В. Тютина, благодаря которым во многом и появилась квантовая теория калибровочных полей. Развитые им методы квантования систем со связями давно проникли практически во все области современной математической физики, на языке работ Тютина уже говорят не только физики, но и математики.

В совместной работе И. И. Собельмана и И. В. Тютина (1964 г.) было показано, что усиление падающего излучения, явление индуцированного излучения, может быть описано в рамках не только квантовой, но и классической теории. В совместной с Е. С. Фрадкиным работе (1970 г.) получено, что правила квантования калибровочных теорий, известные к тому времени только для сингулярных калибровок, 
могут быть обобщены на случай калибровок типа фейнмановских, что позволило формулировать квантовые калибровочные теории поля в терминах локального эффективного действия в произвольной калибровке.

В 70-80-е годы в совместном с Б.Л. Вороновым и П. М. Лавровым цикле работ была установлена структура перенормировки калибровочных теорий общего вида: перенормировка может быть интерпретирована как некоторая специальная (каноническая) замена переменных и параметров теории, причем перенормировка калибровочно-инвариантных физических величин и соответствующие бета-функции не зависят от калибровки (премия им. И.Е. Тамма РАН за 2001 г.). В 90-е годы (в совместных работах с И. А. Баталиным и П. М. Лавровым) были построены обобщения методов квантования калибровочных теорий Баталина-Вилковыского-Фрадкина и доказана эквивалентность лагранжева и гамильтонова квантований калибровочных теорий общего вида.

В совместном с С. Е. Конштейном и А. Г. Смирновым цикле работ (2001- 2009 гг.) по деформационному (звездочному) квантованию найден общий вид деформаций некоторых ассоциативных супералгебр (алгебр Березина), суперскобок Пуассона и антискобок, а также установлено существование деформаций суперскобок Пуассона, не эквивалентных известному мойяловскому, и нетривиальных деформаций антискобок.

Совместный с Б.Л. Вороновым, Д. М. Гитманом и А.Г. Смирновым цикл работ (2006-2013 гг.) посвящен математически строгой формулировке и решению задач нерелятивистской и релятивистской квантовой механики в сильно сингулярных потенциалах на основе теории самосопряженных расширений симметрических операторов и метода Крейна направляющих функционалов. В частности, в этих работах показано, что известная релятивистская кулоновская задача с "закритическим" зарядом допускает корректную формулировку и решение. Важной особенностью квантово-механических задач с сильно сингулярными потенциалами является неоднозначность их формулировки, связанная с необходимостью доопределения поведения частиц в окрестности сингулярности.

Наиболее ярким результатом И. В. Тютина, ставшим всемирно известным (премия Д. Хейнемана по математической физике Американского физического общества за 2009 г.), является открытие в 1975 году так называемой БРСТ-симметрии (симметрии Бекки-Руэ-Стора-Тютина) - а именно, суперсимметрии, которой обладает эффективное действие любой квантовой калибровочной теории, включающее вспомогательные духовые поля. Эта симметрия позволяет построить расширенное квантовое действие по действию исходной классической теории, при этом важную роль в интерпретации физических состояний квантовой теории играет соответствующий сохраняющийся нётеровский БРСТ-заряд, который оказывается нильпотентным. В настоящее время БРСТ-симметрия составляет основу построения и физической интерпретации квантовых калибровочных теорий поля, а также эффективно применяется, например, в двумерной конформной теории поля и ряде других формализмов в теории струн.

Игорь Викторович по сути дела воспитал целое научное поколение, создал научную среду не только в Москве, но и за Уралом. Его авторитет непререкаем в научном и человеческом смысле (даже несмотря на "отсутствие обертонов в голосе"), постоянно растет число проблем, по которым "необходимо посоветоваться 
с Тютиным". Незаменимы вопросы Игоря на научном семинаре, неоценима его роль в работе редколлегии нашего журнала.

Журнал "Теоретическая и математическая физика" представляет специальный сборник, посвященный 75-летию Игоря Викторовича Тютина. В этот сборник вошли статьи его соавторов и учеников, ближайших коллег по работе в Физическом институте им. П.Н. Лебедева и в нашем журнале, написанные по приглашению редакционной коллегии. Из-за ограниченного объема тома он не смог вместить всех желающих, и публикация статей, посвященных 75-летию И. В. Тютина, продолжится в следующем выпуске. Хотелось бы особо отметить участие в "сборнике Тютина" молодых ученых - тех, кто, во многом следуя развитию его идей и принципов, уже определяют будущее современной науки.

Редакционная коллегия, пользуясь случаем, еще раз присоединяется к поздравлениям авторов этого выпуска и желает Игорю Викторовичу дальнейших научных и творческих успехов!

Редколлегия ТМФ 